BLS 34, No 1 2008. DOI: http://dx.doi.org/10.3765/bls.v34i1.3554

(published by the Berkeley Linguistics Society and the Linguistic Society of America)

\title{
Palatalization as Overlap of Articulatory Gestures: Crosslinguistic Evidence
}

\author{
NICOLETA BATEMAN \\ California State University, San Marcos
}

\section{Introduction}

This paper addresses an asymmetry in the behavior of labial consonants with respect to two types of palatalization, full and secondary. Full palatalization involves consonants being articulated within the palatal region of the vocal tract when adjacent to a palatal vocoid such as $i, e, j$, as in (1). Secondary palatalization involves consonants acquiring a secondary palatal articulation in the same context, as in (2):

Full palatalization:

$$
\begin{array}{lll}
\text { [kifet }] & \text { 'open!' (masc. sg. Imperative) } & \text { (Amharic, Ethiopia) } \\
\text { [kifetfi }] \quad \text { 'open!' (fem. sg. Imperative) }
\end{array}
$$

\section{Secondary palatalization:}

/jamati/ [jamat ${ }^{\mathrm{j}} \mathrm{i}$ ] 'a person' (Watjarri, Australia)

Palatalization has been reported to affect consonants at the three major places of articulation, labial, coronal, and dorsal, in asymmetrical ways. For example Bhat (1978), whose crosslinguistic survey presents 120 instances of various types of palatalization, finds that secondary palatalization is common for consonants at all three places of articulation, while what I call full palatalization is common for coronal and dorsal consonants, but rare for labial consonants. He reports only five languages with labial full palatalization: the Moldavian dialect of Romanian (Romance, Romania), Tswana (Southern Bantu, Botswana), Lumaasaba (Narrow Bantu, Uganda), Fula (Niger Congo, Cameroon), and Chontal (Hokan, Mexico). This suggests that labials are more resistant than coronals and dorsals to full palatalization, or shifting to coronal articulations. In addressing the issue of labial to coronal shifts, particularly those in Southern Bantu, Ohala (1978) proposes a perceptual explanation: labials followed by a palatal glide can be directly perceived as coronals. 


\section{Nicoleta Bateman}

Two questions arise as a result of Bhat's (1978) generalizations about the prevalence of full and secondary palatalization and Ohala's (1978) perceptual explanation of labial to coronal shifts. First, why is there an asymmetry between full and secondary palatalization for labial consonants? And second, if labial full palatalization is perceptually motivated, why is it so rare?

Answers to both of these questions are informed by a new crosslinguistic study of palatalization (Bateman 2007a). For this study I surveyed 117 languages from 86 genera (language subfamilies, such as Germanic or Romance, Dryer 1989), geographically and areally balanced. Of these, 58 show some type of palatalization, and 59 do not. Tables (3) and (4) below summarize the number of languages/dialects where full and secondary palatalization is found, grouped according to major place of articulation.

(3) Full palatalization

\begin{tabular}{|l|c|c|c|c|c|c|c|}
\hline $\begin{array}{l}\text { POA } \\
\text { affected } \\
\text { in a given } \\
\text { language }\end{array}$ & $\begin{array}{c}\text { Only } \\
\text { Labial }\end{array}$ & $\begin{array}{c}\text { Only } \\
\text { Coronal }\end{array}$ & $\begin{array}{c}\text { Only } \\
\text { Dorsal }\end{array}$ & $\begin{array}{c}\text { Coronal } \\
+ \\
\text { Dorsal }\end{array}$ & $\begin{array}{c}\text { Labial } \\
+ \\
\text { Dorsal }\end{array}$ & $\begin{array}{c}\text { Labial } \\
+ \\
\text { Coronal }\end{array}$ & $\begin{array}{c}\text { Labial, } \\
\text { Coronal, } \\
\text { Dorsal }\end{array}$ \\
\hline Total & 0 & 27 & 9 & 12 & 0 & 0 & 2 \\
\hline
\end{tabular}

Table (3) shows that coronal and dorsal consonants can undergo independent or co-occurring full palatalization in a language, while labial full palatalization always co-occurs with full palatalization of both coronal and dorsal consonants. There are only two languages in this sample where labials fully palatalize, the Moldavian dialect of Romanian, and Tswana, and there is no language where labials alone or labials and either coronals or dorsals show full palatalization.

(4) Secondary palatalization

\begin{tabular}{|l|c|c|c|c|c|c|c|}
\hline $\begin{array}{l}\text { POA } \\
\begin{array}{l}\text { affected } \\
\text { in a } \\
\text { given } \\
\text { language }\end{array}\end{array}$ & $\begin{array}{c}\text { Only } \\
\text { Labial }\end{array}$ & $\begin{array}{c}\text { Only } \\
\text { Coronal }\end{array}$ & $\begin{array}{c}\text { Only } \\
\text { Dorsal }\end{array}$ & $\begin{array}{c}\text { Coronal } \\
+ \\
\text { Dorsal }\end{array}$ & $\begin{array}{c}\text { Labial } \\
+ \\
\text { Dorsal }^{1}\end{array}$ & $\begin{array}{c}\text { Labial } \\
+ \\
\text { Coronal }^{1}\end{array}$ & $\begin{array}{c}\text { Labial, } \\
\text { Coronal, } \\
\text { Dorsal }\end{array}$ \\
\hline Total & 0 & 7 & 9 & 3 & 2 & 4 & 10 \\
\hline
\end{tabular}

Table (4) shows that, as with full palatalization, coronal and dorsal consonants can undergo independent or co-occurring secondary palatalization in a given language. The greatest difference involves labial consonants, as there are many more cases of secondary palatalization of labials (16 total). Nevertheless, even secondary palatalization of labials must co-occur with the palatalization of coronal and dorsal consonants, as noted by the asterisk in the third- and second-

\footnotetext{
${ }^{1}$ All of these cases have full palatalization of the third place of articulation
} 


\section{Palatalization as Overlap of Articulatory Gestures}

to-last columns of table (4), which indicates that in those languages where labials and either coronals or dorsals show secondary palatalization, the third place of articulation shows full palatalization. For example, in Zoque only labials and dorsals undergo secondary palatalization, while coronals undergo full palatalization.

The generalizations presented above reveal a striking pattern that positions labials against all other consonants. This suggests that the underlying issue relating full and secondary palatalization to the labial, coronal, and dorsal places of articulation must reside in some major difference between labial and non-labial sounds.

In the following sections I argue that palatalization is primarily an articulatory process, formally expressed as temporal overlap of articulatory gestures of the tongue and the lips (in the sense of Browman and Goldstein 1986, inter alia), thus capturing a major distinction between labials and non-labials: the former are articulated with the lips, while the latter are not. I show that this articulatory proposal makes the correct predictions regarding full and secondary palatalization for all consonants, and also explains the rarity of full labial palatalization. In particular, the model predicts that consonants at all three places of articulation should undergo secondary palatalization, and that only coronals and dorsals, but not labials, should undergo full palatalization. This prediction is reconciled with the attested cases of labial full palatalization via a diachronic explanation: for both Moldavian Romanian and Tswana there is historical evidence which demonstrates that labial consonants themselves did not undergo a change. Rather, a palatal glide that followed the labials progressively hardened to the palatal sound we see synchronically, followed by the deletion of the labial.

\section{Current Proposal}

I propose that the general patterns of palatalization as well as the particular patterns of labial palatalization are best explained by referring to the oral articulators lips and tongue and their interaction during speech production. The formal model is couched in Articulatory Phonology (AP; Browman and Goldstein 1986, Byrd 1996, Kochetov 1998, Gafos 2002), a framework that provides a straightforward explanation for phonological processes such as palatalization. In brief, full palatalization results from a high degree of temporal overlap of tongue-tongue gestures, while secondary palatalization results from a minimal degree of temporal overlap of tongue-tongue or lips-tongue gestures.

\subsection{Background on Articulatory Phonology}

In Articulatory Phonology the gesture is the main unit of phonological contrast. A gesture is specified in terms of an articulator (the lips, the tongue tip - TT, and the tongue body- TB), a constriction location (CL), which is roughly equivalent to place of articulation, and a constriction degree (CD), roughly equivalent to manner of articulation. In (5) I provide examples of gestural specifications for [t], [i], [t $]$, a palatalization target, trigger, and outcome, respectively: 


\section{Nicoleta Bateman}

(5) [t] gesture: TTCL [alveolar], TTCD [closed]

[i] gesture: TBCL [palatal], TBCD [narrow]

[ff] gesture: TBCL [alveo-palatal], TBCD [closed-critical]

In addition, gestures have a duration. As speech unfolds in real time consonant and vowel gestures must coordinate with one another, and as a result they can overlap in time. This type of gestural coordination, expressed as temporal overlap, explains phonological processes.

A gesture can be represented as in (6), using articulatory landmarks such as the onset, target, c-center (closure phase), and release phases of the gesture, shown horizontally on a temporal axis (Gafos 2002).

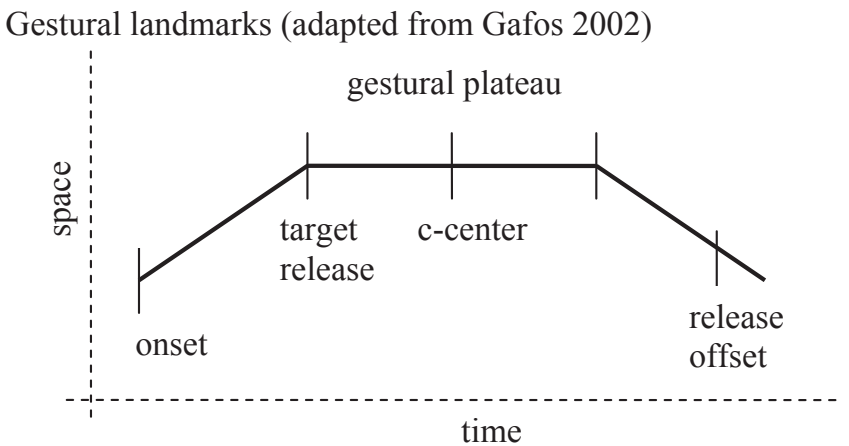

\subsection{An Articulatory Model of Palatalization}

Full and secondary palatalization can be profitably viewed as the outcome of gestural coordination resulting from temporal overlap (see also Kochetov 1998, Davidson 2003). As shown in (7), I propose that in full palatalization the onset phase of the vocalic gesture (dotted line) is synchronized with the c-center phase of the consonantal gesture (solid line), representing a high degree of temporal overlap. The c-center is a general landmark, the key idea being that the onset of the vocoid gesture is synchronized with some point during the closure phase of the consonantal gesture, which is within the c-center landmark phase. This is compatible with Byrd's (1996) phase window model, where variability in temporal coordination of gestures is attributed to windows in the confines of which other gestures can "begin". This temporal overlap pattern results in undershoot of the consonantal target, as the gesture of the consonant blends with that of the following vocoid. 


\section{Full palatalization}

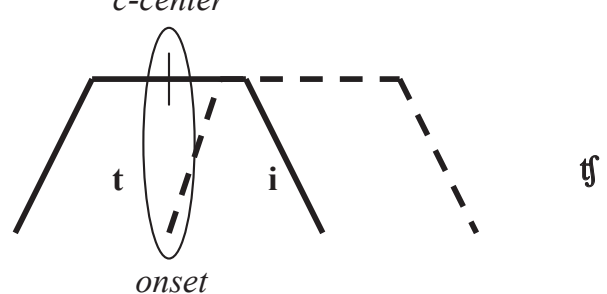

On the other hand, in secondary palatalization the onset phase of the vocalic gesture (dotted line) is synchronized with the release phase of the consonantal gesture (solid line), as in (8). This represents a minimal degree of temporal overlap, where the consonant is fully articulated and also has a secondary tongue body palatal articulation.

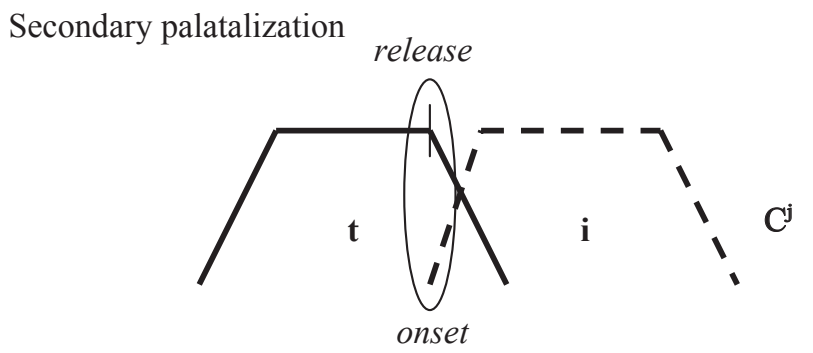

While the representations in (7) and (8) illustrate the general pattern of gestural overlap proposed for full and secondary palatalization, they alone do not explain the particular patterns of palatalization observed. For example, one might expect any consonant to show full palatalization provided that the consonantal and vocalic gestures are synchronized as in (7), leaving the rarity of labial full palatalization unmotivated.

I propose that both the general palatalization patterns and the particular behavior of the labials can be explained by referencing the oral articulators involved in consonantal (target) gestures and vocalic (trigger) gestures, and gestural coordination. As already mentioned, the major articulators in AP are the lips, the tonguetip and the tongue-body. However, typological evidence regarding palatalization provides support for positing a separate tongue articulator, which subsumes tongue-tip and tongue-body as sub-articulators. Browman and Goldstein (1989) also explored the notion of a Tongue node for similar purposes. Thus, labial consonantal targets are articulated with the lips, while coronal and dorsal consonantal targets are articulated with the tongue. The vocalic palatalization triggers, such as $i, e, j$, are all articulated with the tongue; therefore, coronals, dorsals, and palatalization triggers share the same major articulator, the tongue, separating them from the labials which alone use the lips. I argue that the distinct behavior of 


\section{Nicoleta Bateman}

labials with respect to both full and secondary palatalization resides in this very difference in target and trigger articulators, and I propose that which articulators are involved in gestural coordination will affect the potential degree of temporal overlap and therefore the type of palatalization outcome.

If adjacent gestures use the same articulator, the tongue, there is great pressure for them to perturb each other, and as a result they can overlap to different degrees. A minimal degree of temporal overlap, as that occurring when the onset phase of the vocoid gesture is synchronized with the release phase of the consonantal gesture, results in secondary palatalization:

$$
\begin{aligned}
& \text { Minimal temporal overlap (V-onset, C-release) } \\
& \mathrm{t}+\mathrm{i} \quad \rightarrow \mathrm{t}^{\mathrm{j}} \\
& \mathrm{k}+\mathrm{i} \quad \rightarrow \mathrm{k}^{\mathrm{j}}
\end{aligned}
$$

A greater degree of overlap, as that occurring when the onset phase of the vocoid gesture is synchronized with some point in the c-center (closure) phase of the consonantal gesture, results in full palatalization:

$$
\begin{aligned}
& \text { Greater temporal overlap (V-onset, C-center) } \\
& \mathrm{t}+\mathrm{i} \quad \rightarrow \mathrm{t} \mathrm{i} \\
& \mathrm{k}+\mathrm{i} \rightarrow \mathrm{t} \mathrm{i}
\end{aligned}
$$

On the other hand adjacent gestures using different articulators, the lips and the tongue, are under no pressure to perturb each other, as each articulator can move independently of the other. For this very reason lips and tongue gestures can overlap in time, as one can have simultaneous lip closure and tongue movement. I argue that a minimal degree of temporal overlap of lips and tongue gestures can result in a secondarily palatalized labial, but that any greater degrees of temporal overlap of such gestures will result in no palatalization at all.

$$
\begin{aligned}
& \text { Minimal temporal overlap (V-onset, C-release) } \\
& \mathrm{p}+\mathrm{i} \rightarrow \mathrm{p}^{\mathrm{j}} \\
& \text { Greater temporal overlap (V-onset, C-center) } \\
& \mathrm{p}+\mathrm{i} \rightarrow \mathrm{pi}
\end{aligned}
$$

This model predicts that labial consonants can only undergo secondary palatalization, but not full palatalization. First, given the independence of the target and trigger articulators, there is no articulatory impetus for labials to fully palatalize and shift to tongue-articulations. In other words, there is no pressure for lips and tongue gestures to "blend" and create a new sound. And second, if the lipstongue gestures showed no overlap, c-center overlap, or full overlap, the consonantal outcome would still be a labial, not a coronal palatal consonant as we might expect from full palatalization. 


\section{Palatalization as Overlap of Articulatory Gestures}

For example, in palatalization the lips would be performing the task of lip closure for [p], while the tongue would be performing the task of achieving a palatalization trigger, such as [i]. It follows that if a lips gesture and the following tongue gesture were fully overlapped, the lips gesture would completely obscure that of the tongue, as the lips are physically in front of the tongue. Thus, full overlap of [p] and [i] gestures would result in a [p]. Further, I argue that a great, but not complete, degree of temporal overlap, as associated with full palatalization, would result in a labial followed by the vocoid: [p] + [i] $\rightarrow$ [pi]. With Vonset $\sim \mathrm{C}$-center synchronization, upon the release of the consonant the vocoid gesture is already in motion, and it simply continues after the release of the consonantal gesture in the same way as when the vocoid gesture followed the lips gesture, with no overlap; thus, only the actual vocoid surfaces after the consonantal gesture.

To summarize, I propose that full palatalization results from great overlap of tongue-tongue gestures only, thereby predicting that coronals and dorsals, but not labials, should show full palatalization. Great overlap is defined as the synchronization of the vocoid gesture onset phase with the c-center phase of the consonantal gesture. Furthermore, I propose that secondary palatalization results from minimal overlap of lips-tongue or tongue-tongue gestures, thereby predicting that coronals, dorsals, and also labials should show secondary palatalization. Minimal overlap is defined as the synchronization of the vocoid gesture onset phase with the release phase of the consonantal gesture.

By adopting an articulatory approach and referencing the oral articulators and their interaction during speech production, the analysis proposed here explains the general patterns of palatalization emerging from the crosslinguistic study. Specifically, first it provides a straightforward explanation for why coronals and dorsals can undergo both full and secondary palatalization: as coronals and dorsals use the same articulator as the palatalization triggers, the tongue, the degree of gestural temporal overlap will determine the type of palatalization that will result. Second, the analysis also explains why labial consonants undergo secondary palatalization fairly commonly: minimal temporal overlap of lips-tongue gestures can lead to secondarily palatalized labials, where the labial consonant is articulated fully and only has a secondary palatal articulation superimposed on it, but there are no labial to coronal shifts.

In addition, however, the analysis also predicts that labials should not undergo full palatalization, a prediction that must be reconciled with the two attested cases of apparent labial full palatalization, Moldavian Romanian and Tswana. In the following section I present a brief account of full "labial palatalization" in these two languages and show that labial consonants did not actually undergo palatalization themselves. The synchronic labial $\sim$ palatal alternations are reflexes of diachronic developments, and historical evidence thus verifies the prediction of the articulatory model of palatalization. 


\section{Nicoleta Bateman}

\section{Labial "Full Palatalization"}

\subsection{Moldavian Romanian}

In both Standard Romanian and in the Moldavian dialect, all consonants are affected by an underlying /i/ suffix, such as the plural or the $2^{\text {nd }}$ singular of the indicative. Labial consonants show productive secondary palatalization, dorsals show full palatalization, and coronals either fully palatalize or assibilate. Some examples are given in (12) for plural nouns in Moldavian.

$\begin{array}{llll}\mathrm{t} \rightarrow \mathrm{ts} & \text { soldat } & \text { soldats } & \text { 'soldier' } \\ \mathrm{k} \rightarrow \mathrm{S}^{\mathrm{j}} & \text { rak } & \mathrm{raf}^{\mathrm{j}} & \text { 'lobster' } \\ \mathrm{p} \rightarrow \mathrm{p}^{\mathrm{j}} & \text { episkop } & \mathrm{episkop}^{\mathrm{j}} & \text { 'bishop' } \\ \mathrm{b} \rightarrow \mathrm{b}^{\mathrm{j}} & \mathrm{krab} & \mathrm{krab}^{\mathrm{j}} & \text { 'type of fish' } \\ \mathrm{m} \rightarrow \mathrm{m}^{\mathrm{j}} & \text { pom } & \mathrm{pom}^{\mathrm{j}} & \text { 'tree' } \\ \mathrm{v} \rightarrow \mathrm{v}^{\mathrm{j}} & \text { elev } & \mathrm{elev}^{\mathrm{j}} & \text { 'student' } \\ \mathrm{f} \rightarrow \mathrm{f}^{\mathrm{j}} & \int \partial \mathrm{f} & \int \partial \mathrm{f}^{\mathrm{j}} & \text { 'boss' }\end{array}$

In addition, the Moldavian dialect appears to exhibit full palatalization of labials, in that the labial consonants shift to a palatal or secondarily palatalized non-labial consonant, as shown in (13) for definite plural nouns.

$$
\text { Sg. def. Pl. def. }
$$

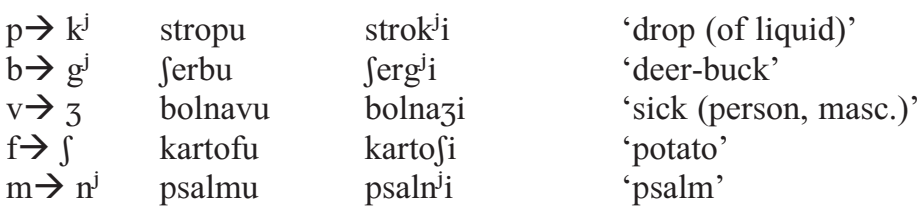

This type of alternation is synchronically productive only via analogy, as labial "full palatalization" is a widely recognized feature of this dialect among Romanian speakers. Two native speakers of Moldavian who were presented with nonce verb forms ending in labial consonants said they would be pronounced with labials in the Moldavian dialect, for example the nonce infinitive [uriba] would be [urig ${ }^{\mathrm{j}}$ ] in the $2^{\text {nd }}$ singular indicative, before the suffix /i/ (Bateman 2007b).

On the surface, alternations such as those in (13) above seem to indicate a productive synchronic process whereby the entire series of labial consonants shifts in a single step to palatal or secondarily palatalized non-labial consonants, contrary to the articulatory prediction outlined in the previous section. However, historical evidence demonstrates that this is not the case. These alternations are the result of a series of sound changes that affected a palatal glide which followed the labial, rather than the labial itself (Ionescu 1969, Avram 1977). The only way that labials were themselves affected was deletion from a labial-palatal cluster. 


\section{Palatalization as Overlap of Articulatory Gestures}

Historical evidence suggests the following progression of sound changes for Moldavian. First, a palatal glide appeared after a labial consonant. The source of this glide is different depending on context, for example it was already present in forms such as [vjer] 'boar', and it was provided by secondary palatalization in plural forms such as [lup j] 'wolves' (Avram 1977, Bateman 2007a). The palatal glide progressively hardened to the palatal or palatalized consonant we see today, assimilating the voicing, continuancy, and nasality features from the labial consonant. Glide hardening produced a labial-palatal(ized) cluster, and finally, the labial consonant deleted from the cluster, leaving only the palatal or palatalized consonant we see today. The labial palatalization steps are summarized in (14) via an example of the "palatalization" of [v] in 'boar':

$$
\text { vjer } \rightarrow \text { vjer } \rightarrow \text { vzer } \rightarrow \text { zer } \quad \text { 'boar' }
$$

This analysis of labial "full palatalization" is supported by the existence of forms at intermediate stages, with labial-palatal(ized) consonant clusters, in other dialects of Romanian and also in the Moldavian dialect itself, as in (15):

\section{Other dialects Moldavian}

\begin{tabular}{|c|c|c|c|}
\hline $\mathrm{p} \rightarrow \mathrm{k}^{\mathrm{j}}$ & kopcil & $\mathrm{kopk}^{\mathrm{j}_{\mathrm{i}} \mathrm{l}}$ & 'child' \\
\hline & lupci & lupk ${ }^{\mathrm{j}} \mathrm{i}$ & 'the wolves' \\
\hline & pkifjor & $\underline{\mathrm{k}^{\mathrm{j}} \overline{\mathrm{i} \int \mathrm{j} o r}}$ & 'leg' \\
\hline & $\mathrm{mn}^{\mathrm{j}} \mathrm{el}$ & $\underline{n^{\mathrm{j}}} \mathrm{el}$ & 'lamb' \\
\hline & $\overline{\text { fqer }}$ & $\bar{z}$ er & 'iron' \\
\hline 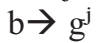 & albjina & algina & 'the bee' \\
\hline
\end{tabular}

In addition, parallel developments in other Romance languages further support this account. For example, Latin labials have palatal reflexes in Modern French (Ohala 1978, Nyrop 1914):

\begin{tabular}{llll} 
Latin & \multicolumn{2}{l}{ Modern French } \\
rŭbĕus & rouge & [вu3] & 'red' \\
răbĭes & rage & {$[\mathrm{ba}]$} & 'rabid' \\
căvĕa & cage & {$[\mathrm{ka3}]$} & 'cave' \\
sapiam & sache & {$[\mathrm{sa}]$} & 'that s/he know'
\end{tabular}

As in Moldavian, the path of sound change from labial to palatal in French also involved glide hardening and labial deletion (Nyrop 1914, Pope 1961):

$$
\begin{aligned}
& \mathrm{pj} \rightarrow \mathrm{pt} \rightarrow \mathrm{t} \rightarrow \int \\
& \mathrm{bj} \rightarrow \mathrm{bd} \rightarrow \mathrm{d} \rightarrow 3
\end{aligned}
$$




\section{Nicoleta Bateman}

To summarize, diachronic evidence supports the prediction of the articulatory account that labial consonants should not undergo full palatalization. As I show in the next section, this is further supported by similar historical developments in Tswana, a language genetically unrelated to Romanian.

\subsection{Tswana}

Labial consonants also appear to undergo full palatalization in a single step in Tswana passives, causatives, and diminutives. Some examples of diminutive forms with the suffix - ana are provided below. Forms with a coronal and a dorsal consonant are given for comparison, to show that they also undergo full palatalization (Cole 1955; Sound System of Setswana 1999; tones are omitted):

$$
\begin{aligned}
& \mathrm{t} \rightarrow \mathrm{t} f \quad \text { lobati-ana } \quad \rightarrow \text { lobatfana } \quad \text { 'small board/plank' }
\end{aligned}
$$

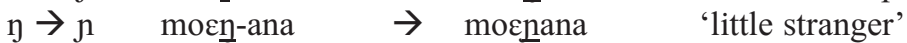

$$
\begin{aligned}
& \mathrm{p} \rightarrow \mathrm{t}^{\mathrm{w}} \mathrm{tl}^{\mathrm{h}} \text { api-ana } \quad \rightarrow \mathrm{tl}^{\mathrm{h}} \mathrm{at} \mathrm{f}^{\mathrm{w}} \mathrm{a} \text { :na } \quad \text { 'small fish' }
\end{aligned}
$$

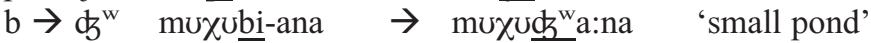

$$
\begin{aligned}
& \phi \rightarrow \mathrm{tg}^{\mathrm{hw}} \text { muraфi-ana } \rightarrow \text { murat } \text { f }^{\mathrm{hw}} \mathrm{a} \text { :na 'small nation' }
\end{aligned}
$$

As with Romanian, these changes did not occur in a single step but rather via intermediary stages of glide hardening and labial deletion. I propose that in the diminutive the final stem vowel first became a glide. This glide progressively hardened, assuming voicing from the labial consonant, while labialization resulted from lip rounding that persisted throughout the production of the labial-palatal cluster (Ohala 1978 also mentions persistent lip rounding). Finally, the labial consonant deleted, leaving only the palatal consonant which is seen today. An example is given below for [tshit ${ }^{\mathrm{w}}$ ana] 'small piece of iron' (tones omitted):

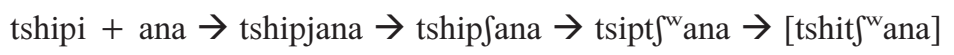

Evidence of glide hardening comes from Cole (1955), who provides alternative forms in Tswana dialects with labial-palatal clusters, as summarized in (20).

\begin{tabular}{|c|c|c|c|c|c|c|}
\hline & \multicolumn{3}{|c|}{ Passive forms in Tswana dialects } & \multicolumn{3}{|c|}{ Diminutive forms in Tswana dialects } \\
\hline $\mathrm{p}$ & $\mathrm{tg}^{\mathrm{w}}$ & $p \int^{w}$ & $\mathrm{ps}^{\mathrm{w}}$ & $\mathrm{tg}^{\mathrm{w}}$ & $p \int^{\mathrm{w}}$ & $\mathrm{p} \int$ \\
\hline $\mathrm{b}$ & $\mathrm{s}^{\mathrm{w}}$ & $\mathrm{bc} \mathrm{s}^{\mathrm{w}}$ & & $\mathrm{s}^{\mathrm{w}}, \mathrm{s}$ & bs ${ }^{n}$ & $\mathrm{bc}$ \\
\hline $\mathrm{p}^{\mathrm{h}}$ & $\mathrm{tg}^{\mathrm{hw}}$ & $\mathrm{p} \int^{\mathrm{hw}}$ & & $t^{\text {hw }}$ & $\mathrm{p} \int^{\mathrm{hw}}$ & $\mathrm{p} \int^{\mathrm{h}}$ \\
\hline$\phi$ & $\int^{\mathrm{w}}$ & $\phi \int^{\mathrm{w}}$ & & $\int^{\mathrm{w}}$ & & \\
\hline
\end{tabular}

Prior analyses of labial palatalization in Tswana include misperception (Ohala 1978) and mutation (LaCharité 1993). Ohala (1978) proposes that a labial followed by a palatal glide can be directly perceived as a palatal, with no need for intermediate stages. However, the presence of forms at intermediate stages 


\section{Palatalization as Overlap of Articulatory Gestures}

suggests otherwise. Furthermore, an analysis based on misperception does not explain why such cases are so rare. LaCharité (1993) proposes an analysis whereby the causative is a floating feature [+strident] that is sometimes associated with the final stem consonant to produce palatalization. This approach suggests that palatalization is the realization of morphology, and furthermore the association of the floating feature with final stem consonants seems arbitrary (Bateman 2007a).

In this section I showed that the apparent direct change from labial to palatal or palatalized consonant in Moldavian and Tswana is in fact the synchronic reflex of a series of diachronic sound changes that did not involve the labial consonant except in the final stage when it was deleted. The diachronic evidence presented above supports the articulatory analysis of palatalization and reconciles the prediction that labials should not undergo full palatalization with the apparent attested cases in the crosslinguistic study.

\section{Conclusion}

In this paper I proposed an articulatory account of palatalization, whereby full and secondary palatalization are viewed as resulting from different degrees of temporal overlap of articulatory gestures of the palatalization consonantal targets and vocoid triggers. Viewed as the result of articulatory overlap, the general patterns of full and secondary palatalization that emerged from the crosslinguistic study can be explained straightforwardly. First, coronal, dorsal, and labial consonants are all predicted to show secondary palatalization, as this results from a minimal degree of temporal overlap of tongue-tongue or lips-tongue gestures. Second, only coronal and dorsal consonants are expected to undergo full palatalization, as this arises from greater degrees of temporal overlap of tongue-tongue gestures, thus predicting that labial consonants should not undergo full palatalization. I showed how this prediction is reconciled with the apparent attested cases of labial full palatalization by appealing to historical evidence that indicates that the labial consonants themselves did not change, but rather a following palatal glide did.

The articulatory account thus provides clear answers to both questions addressed in the paper. First, the asymmetry between full and secondary palatalization for labial consonants results from which articulators are used (lips or tongue), and the degree of temporal overlap that occurs. And second, the rarity of labial full palatalization results from the fact that labials do not fully palatalize at all. Thus, the articulatory account is superior to a perceptual one because it not only makes the right predictions regarding the crosslinguistic palatalization patterns, but also provides an explanation for them.

\section{References}

Avram, Andrei. 1977. Preliminaries to a Classification of Daco-Romanian Dialects Based on Labial Palatalization. Studii si Cercetari Lingvistice 3, 217 - 


\section{Nicoleta Bateman}

288, Bucharest.

Bateman, Nicoleta. 2007a. A Crosslinguistic Investigation of Palatalization. Ph.D. diss., University of California, San Diego.

Bateman, Nicoleta. 2007b. Palatalization in Moldavian Verbs: Centrality of the Infinitive Base. LSRL 37, Pittsburgh, PA. March 17, 2007.

Bhat, D.N.S. 1978. A General Study of Palatalization. In Greenberg, ed., Universals of Human Language, 47-92.

Browman, Catherine P. and Louis Goldstein. 1986. Towards an Articulatory Phonology. Phonology Yearbook 3, 219-252.

Browman, Catherine P. and Louis Goldstein. 1989. Articulatory Gestures as Phonological Units. Phonology 6, 201-251.

Byrd, Dani. 1996. A Phase Window Framework for Articulatory Timing. Phonology 13(2), 139-169.

Cole, Desmond T. 1955. An Introduction to Tswana Grammar. Longman.

Davidson, Lisa. 2003. Articulatory and Perceptual Influences on the Production of Non-Native Clusters. In Proceedings of the $15^{\text {th }}$ International Congress of Phonetic Sciences. Barcelona, Spain, August 3-9.

Dryer, Matthew S. 1989. Large Linguistic Areas and Language Sampling. Studies in Language 13-2, 257-292.

Gafos, Adamantios I. 2002. A Grammar of Gestural Coordination. Natural Language and Linguistic Theory 20 (2), 269-337.

Ionescu, Liliana. 1969. Palatalizarea labialelor în graiurile din Moldova. In Fonetica şi Dialectologie VI, 49-57.

Kochetov, Alexei. 1998. Labial Palatalization: A Gestural Account of Phonetic Implementation. The Canadian Linguistics Association Annual Proceedings, 38-50.

LaCharité, Darlene. 1993. On the Need for Negative Constraints and Repair: Consonant Mutation in Setswana. In Carole Paradis and Darlene LaCharité, eds., The Canadian Journal of Linguistics.

Nyrop, K.R. 1914. Grammaire Historique de la Langue Française. Copenhague.

Ohala, John J. 1978. Southern Bantu vs. the World: The Case of Palatalization of Labials. BLS 370-386.

Pope, Mildred K. 1961. From Latin to Modern French with Especial Consideration of Anglo-Norman. Phonology and Morphology. Manchester University Press.

The Sound System of Setswana. 1999. Department of African Languages and Literature, University of Botswana.

Department of Liberal Studies

California State University, San Marcos

333 S. Twin Oaks Valley Road

San Marcos, CA 92096

nbateman@csusm.edu 